\title{
A study to assess the patterns of self medication practice among women employees working in health care services \\ Sheik Abdul Hafeez ${ }^{1,2^{*}}$, Mary Jyotsna $\mathbf{M}^{1}$, and Ramanamurthy $\mathbf{K V}^{3}$ \\ ${ }^{1}$ Academics Wing,, OMNI Hospitals, Hyderabad-500102, Telangana State, India \\ ${ }^{2}$ Department of Biotechnology, Acharya Nagarjuna University, Guntur-522510, Andhra Pradesh, India \\ ${ }^{3}$ Department of Pharmaceutical Technology, A.U. College of Pharmaceutical Sciences, Andhra University, Visakhapatnam-530003, Andhra Pradesh, India
}

\begin{abstract}
Objective: To assess the patterns of self medication practice among women employees working in health care services

Study design: A non experimental survey approach with descriptive design was selected to understand the patterns of self medication among women employees working in health care services. Study was conducted in OMNI group of Hospitals, Hyderabad, India.

Methods: Interview schedule was prepared with systematic reviewed literature and data was obtained from 600 sample selected using convenient sampling technique. Collected data was analyzed with descriptive and inferential statistics using statistical package for the social sciences software version-20. Graphical representation was made for significant findings.
\end{abstract}

Results: Women employees under study, 437 (72.8\%) stated that they are self medication users which was considerably the highest percentage, majority 250(41.7\%) of them have family and friends as there source of knowledge. The study results showed that majority of the sample are using self medication in specific patterns. It also proved that maximum number of sample i.e., 455 (75.8\%) inform the physician about self medicated drugs on consultation, 434 (72.3\%). Procure drug only from pharmacy, 424 (70.7\%) avoid self medication with old prescription and 419 (69.8\%) stated that they avoid sharing drugs prescribed to someone else.

Conclusion: Self medication is widely practiced among women employees in health care services and is an emerging cause of self induced risk factor for healthy living, due to the knowledge and hand to hand availability of drugs.

Keywords: self medication; women employees; patterns of self medication practice

*Corresponding author: Dr. Sheik Abdul Hafeez, MSc., PhD., MA., MBA., Principal, Academics Wing,, OMNI Hospitals, Hyderabad500102, Telangana State, India. Email: hafeez@omnihospitals.in

Received 28 September 2020; Revised 18 November 2020; Accepted 2 December 2020; Published 12 December 2020

Citation: Hafeez SA, Jyotsna MM, Ramanamurthy KV. A study to assess the patterns of self medication practice among women employees working in health care services. J Med Sci Res. 2021; 9(1):11-17. DOI: http://dx.doi.org/10.17727/JMSR.2021/9-3

Copyright: (C) 2021 Hafeez SA et al. Published by KIMS Foundation and Research Center. This is an open-access article distributed under the terms of the Creative Commons Attribution License, which permits unrestricted use, distribution, and reproduction in any medium, provided the original author and source are credited. 


\section{Introduction}

Self medication is known as the treatment of certain health problems or issues with medications particularly designed and labelled for use without medical supervision and approved as safe and effective for such use [1]. Self medication is a human practice in which an individual uses a substance or any exogenous influence to self administers treatment for physical or psychological ailments. Medicines for self medication are often called 'nonprescription' or 'over the counter' (OTC) drugs and is available without a doctor's prescription through pharmacies. In some countries 'over the counter' OTC products are also available in supermarkets and other general outlets. Medicines that require a doctor's prescription are called prescription products and treatment products [1].

According to the WHO's definition, self medication is the use of drugs to treat self-diagnosed disorders or symptoms, or the intermittent or continued use of a prescribed drug for chronic or recurrent diseases or symptoms.

Medication usage refers to the human act of in taking medicines for prevention, diagnosis or treatment of illness, diseases in acute or chronic forms. Intake or consumption of correct medication should be periodically monitored by health-care personnel's. The person who is using self medicines report if any harmful symptoms reported back to the health care personnel who can further diagnose and prescribe the needed drugs to alleviate the unwanted symptoms [2]. Over the counter (OTC) drugs are a form of self medication. The buyer diagnoses his/ her own illness and buys a specific drug to treat it [2].

OTC products provide symptom relief for conditions that do not always require medical intervention. A person with minor illness like fever, common cold, cough, diarrhoea, wounds, infections, stomach upset like nausea, vomiting, and constipation might receive suggestions and advice from family, friends, or even total strangers in India near or far about medicines, specially about usage of antibiotics [3]. Factors influencing frequency of self medication in the previous studies are age, educational level, family attitudes, advertising of drug manufacturers, legislation regulating dispensing and sale of drugs, previous experiences with the symptoms or disease, significance attributed to the disease [4] and economic situation of respondents [5].

Such persons with minor illness will either consult a medical shop, drug store (retail pharmacy) and obtain medicine, or discuss with elders of family or a neighbour who may have some tablets left over from their previous illness and thus procure the medicine from them i.e., elders of family or a neighbour [6].

Every day, everywhere, consumer's, patients or persons reach for self care products to help them through their common health problems. They do so because it may be easier for them, it may be more cost or time efficient, they may not feel their situation merits making an appointment with a healthcare professional, or they may have few or no other options. The challenge and opportunity for governments, healthcare professionals, and providers of self medication products is more [7].

There is evidence that consumers patients or persons can do practice self medication responsibly. There is also support showing consumers recognize and respect non prescription medicines. As a whole, they use them appropriately, carefully, and safely; and they read non prescription drug labelling.

Self care perform remain defined as much a most important populace fitness resource between the health care system. It concerns the health things to do yet health choices regarding men and women or includes self medication, self-treatment, conventional aid into illness, or first aid among everyday life. The choice in conformity to allow products in self medication through OTC sale is currently large activity in several countries. Drug regulatory and health authorities need to think about the kinds of medicinal products \& ways of their marketing is appropriate, safe \& rational towards the public health. It has become extensively popular that self medication has a necessary role in practice of move within the health care system. Recognition of the responsibility about persons for their personal health, or awareness so much expert care because minor illnesses is often needless hold contributed to this view $[8,9]$. For the conduction of present study intense review of those studies has been carried out in five categories, and findings obtained in previous studies, gave an idea of conducting the study. Major studies concluded that the practice of self medication was more in women to men and more 
over researcher observed that some of the women colleagues in working place practice self medication and hence the present study was considered as choice of obtaining findings in working women in health care services in Hyderabad.

\section{Methodology}

A non experimental survey approach with descriptive design was selected to understand the patterns of self medication practices among women employees working in health care services and also the relationship with variables. Study was conducted in OMNI Hospitals, Hyderabad, India, with formal approval from Institutional Ethical Committee from 14-02-2017 to 16-08-2017. Interview schedule (questionnaire) was prepared and data was collected with due consent from 600 sample selected using convenient sampling technique. All the respondents actively participated in the study and it took about 30-45 minutes to collect the required data from each participant. Collected data was analyzed with the help of descriptive and inferential statistics. Results were inferred at respective level of significance using statistical package for the Social Sciences Software version-20. Graphical representation was made for significant findings.

\section{Results}

The methods of analysis chosen for the present study depend on the objectives, hypotheses, the purpose and use of the study.

The data was entered in the master sheet for analysis and interpretation. It was done with the help of description and inferential statistics to examine the objectives and to test the hypothesis of the study. Data was coded and processed. Data was computed by using descriptive and inferential statistical procedures. Descriptive statistical procedures used were calculation of frequency, percentage, mean and standard deviation. Inferential statistical methods used were Chi Square test and ANOVA.

Results states that majority of the women employees $437(72.8 \%)$ stated that they are self medication users and $163(27.8 \%)$ respondents said that they are non on direct self medication but on the medication prescribed to them long back and they use the same medicine at times when required. When coming to the variable occurrence of frequent illness, 197 $(32.8 \%)$ responded that they are having illness as frequent as less than 15 days due to their inherited immunity followed by 178 (29.7\%) said they have illness in 60-120 days frequency, 131(21.8\%) with 30-60 days frequency and only 94 responded as 1530 days frequency of occurrence if illness leading to self medication.

When the type of illness was taken into consideration, out of 600 women employees, 210 said allergies as major type of illness for which they use self medication, $184(30.7 \%)$ as respiratory infections, $108(18.0 \%)$ with physical insomnia, 89 (14.8\%) with occupational body aches and only 9 (1.5\%) responded as other un mentioned reasons as menstrual pain and skin sores.

Study also shows the data pertaining to self medication type. It explains that 274 (45.8\%) women use drugs under schedule G, 114 (19.0\%) use schedule H drugs, 110 (18.3\%) are OTC drug users and 102 (17.0\%) use drugs under category of Ayurvedic and Homeopathic medicines.

When the sample where analyzed based on their sources of knowledge regarding self medication, the following conclusions were drawn. Majority $250(41.7 \%)$ of them have family \& friends as there source of knowledge, 248 (41.3\%) as books, $65(10.8 \%)$ have mass media as source in gaining knowledge regarding medications and 37 (6.2\%) as lectures heard in study time as knowledge source.

It also describes that majority of the women employees 312 (52.0\%) are in 18-25 years age group followed by 246 (41\%) in 26-35 years age, 34 (5.7\%) in 36-45 years and only $08(1.3 \%)$ belong to 46 years and above age group. It also gave a note on area of residence where the sample of the study belong to as majority $362(60.3 \%)$ belonging to urban area and rest 238 (39.7\%) belong to rural area of living.

When the sample where categorized based on their marital status and use of self medication, 263 $(43.9 \%)$ of them were unmarried, $258(43.0 \%)$ were married, $60(10 \%)$ were single and 19 (3.1\%) of them were widowed and majority of the women employees of study i.e., 431 (71.9\%) have graduation as their educational qualification, 79 $(13.1 \%)$ are post graduates, 55 (9.2\%) employed based on intermediate education and 35 (5.8\%) with secondary school education working as hospital support system and when compared in religion 
category majority of 423 (70.5\%) were Hindu's, 146 (24.3\%) were Christians, $16(2.7 \%)$ are belonging to other religion groups and 15 (2.5\%) are Muslims, majority of the women employees 408 (68\%) belong to nursing department, 79 (13.2\%) are in hospital support services department, 74 (12.3\%) pharmacy department and 39 (6.5\%) are in to paramedical department which are considered for self medication study.

When the years of experience was taken into consideration, out of 600 women employees, 406 $(67.6 \%)$ are with 1-5 years of experience, 135 (22.5\%) are with 6-10 years experience in hospital area, 33 (5.5\%) with 11-15 years of experience and $26(4.4 \%)$ are with more experience of 16 years and above in their respective areas of work experience in varied health care sectors.

Study also shows the data pertaining to self medication based on family monthly income the following conclusions were drawn. 325 (54.2\%) employees were earning 10,000 to 20,000 rupees per month, 155 (25.8\%) earn rupees 20,001 to $30,000,63(10.5 \%)$ with monthly pay between $30,001-40,000$ rupees and only 57 (9.5\%) with 40,000 rupees and more.

The study results showed that majority of the sample are using self medication in specific patterns. It also proved that majority of them 455 (75.8\%) inform the physician about self medicated drugs on consultation, 434 (72.3\%). Procure drug only from pharmacy, $424(70.7 \%)$ avoid self medication with old prescription and 419 (69.8\%) stated that they avoid sharing drugs prescribed to someone else. Study also concluded that very less number of sample 279 (46.5\%) stated that they avoid taking double dose if symptoms are not treated with recommended dose and $280(46.7 \%)$ said that they quit self medication if symptoms of ailment persists for longer time.

Table 1: Responses of women employees based on practice questions on self medication: Pattern of self medication- $\mathrm{n}=600$.

\begin{tabular}{|c|c|c|c|c|c|}
\hline \multirow{2}{*}{ S. No } & \multirow{2}{*}{$\begin{array}{l}\text { Practice questions on self medication: Pattern of self } \\
\text { medication; do you }\end{array}$} & \multicolumn{2}{|c|}{ Responses yes } & \multicolumn{2}{|c|}{ Responses no } \\
\hline & & $F$ & $\%$ & $F$ & $\%$ \\
\hline 1 & Avoid sharing drugs prescribed to someone & 419 & 69.8 & 181 & 30.2 \\
\hline 2 & Avoid self medication with old prescription & 424 & 70.7 & 176 & 29.3 \\
\hline 3 & $\begin{array}{l}\text { Inform the physician about self medicated drugs on } \\
\text { consultation }\end{array}$ & 455 & 75.8 & 145 & 24.2 \\
\hline 4 & Maintain record of self medicated drugs & 394 & 65.7 & 206 & 34.3 \\
\hline 5 & Procure drug only from pharmacy & 434 & 72.3 & 166 & 27.7 \\
\hline 6 & Avoid taking two different types of drugs at same time & 378 & 63.0 & 222 & 37.0 \\
\hline 7 & $\begin{array}{l}\text { Quit self medication if symptoms of ailment persists for } \\
\text { longer time }\end{array}$ & 280 & 46.7 & 320 & 53.3 \\
\hline 8 & $\begin{array}{l}\text { Avoid changing drug intake from regular prescription to } \\
\text { self medication on sudden contact with new illness }\end{array}$ & 281 & 46.8 & 319 & 53.2 \\
\hline 9 & $\begin{array}{l}\text { Avoid taking double dose if symptoms are not treated } \\
\text { with recommended dose }\end{array}$ & 279 & 46.5 & 321 & 53.5 \\
\hline
\end{tabular}

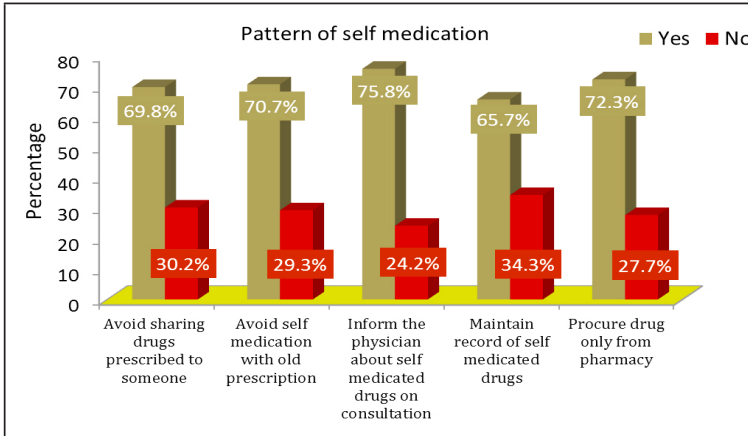

Figure 1: Distributions of women employees according to their practice question - Patterns of self medication.

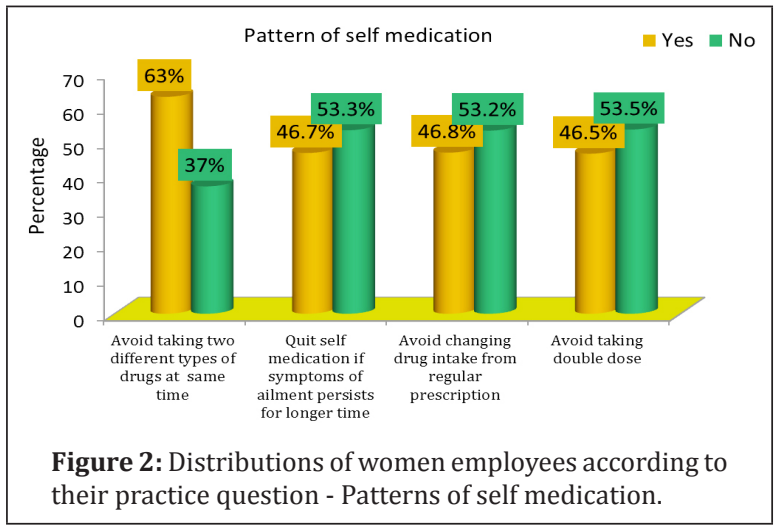

Journal of Medical and Scientific Research 
Table 2: Descriptive data of women employees based on practice questions on self medication. $\mathrm{n}=600$.

\begin{tabular}{|c|c|c|c|c|}
\hline S. No & $\begin{array}{l}\text { Practice questions on self medication: Pattern of self } \\
\text { medication; do you }\end{array}$ & Mean & $\begin{array}{l}\text { Std. deviation } \\
(\sigma)\end{array}$ & Std. error \\
\hline 1 & Avoid sharing drugs prescribed to someone & 0.698 & 0.45936 & 0.01875 \\
\hline 2 & Avoid self medication with old prescription & 0.706 & 0.45567 & 0.01860 \\
\hline 3 & $\begin{array}{l}\text { Inform the physician about self medicated drugs on } \\
\text { consultation }\end{array}$ & 0.758 & 0.42845 & 0.01749 \\
\hline 4 & Maintain record of self medicated drugs & 0.656 & 0.47522 & 0.01940 \\
\hline 5 & Procure drug only from pharmacy & 0.723 & 0.44772 & 0.01828 \\
\hline 6 & Avoid taking two different types of drugs at same time & 0.630 & 0.48321 & 0.01973 \\
\hline 7 & $\begin{array}{l}\text { Quit self medication if symptoms of ailment persists for } \\
\text { longer time }\end{array}$ & 0.466 & 0.49930 & 0.02038 \\
\hline 8 & $\begin{array}{l}\text { Avoid changing drug intake from regular prescription to } \\
\text { self medication on sudden contact with new illness }\end{array}$ & 0.468 & 0.49941 & 0.02039 \\
\hline 9 & $\begin{array}{l}\text { Avoid taking double dose if symptoms are not treated with } \\
\text { recommended dose }\end{array}$ & 0.465 & 0.49919 & 0.02038 \\
\hline
\end{tabular}

Table 3: ANOVA of women employees based on practice questions on self medication, $\mathrm{n}=600$.

\begin{tabular}{|llccccc|}
\hline \multirow{2}{*}{ Variables: Pattern of self medication } & \multicolumn{5}{c|}{ Practice questions on self medication } \\
\cline { 3 - 6 } & & Sum of squares & $d f$ & Mean square & $F$ & $\begin{array}{l}\text { Table } \\
\text { value }\end{array}$ \\
\hline Between people & & 497.8 & 599 & 0.83 & \\
& Between items & 69.2 & 8 & 8.65 & $428.8^{*}$ & 1.95 \\
Within people & Residual & 706.0 & 4792 & 0.14 & \\
Total & Total & 775.3 & 4800 & 0.16 & \\
\end{tabular}

The misuse of non prescription drugs amongst young people has become a serious problem. This raises concerns of incorrect self diagnosis, drug interaction and use other than the original indication. In several studies, it has been found that self medication is associated with many drugs related problems such as wastage of resources, increased resistance of pathogens and serious health hazards such as adverse drug reactions, drug interactions. Even if the drugs were used correctly, self use may result in a number of serious health hazards. Adherence to treatment and quality of life are also affected by self medication.

Self administering of drugs results in many physiological changes that could theoretically affect absorption, first pass metabolism, protein binding, distribution and elimination of the drug. An appropriate dose for one person can be an overdose for another, thus the individual who is ill, advised in subjecting himself to potentially dangerous self medication. A major drawback of self medication is the lack of clinical evaluation of the patients, which could result in misdiagnosis and delay in appropriate treatment. Inappropriate self medication at the community level could lead to the drug induced diseases and waste of expenditure. Since over the counter drugs can be used for self medication without the advice of the physician, their use is often not recorded in the individual medication history. The need to treat OTC drugs like all the other medications and to monitor self medication practices are more and more recognized.

$H_{0}$ : There is no significant association between self medication practice questions like checking drug before administration, pattern of medication, storage of drug, reasons for not consulting a doctor, duration of self medication, reasons in favour of self medication, reasons against self medication, 
drug usage pattern and discontinuation of self medication.

$H_{1}$ : There is significant association between self medication practice questions like checking drug before administration, pattern of medication, storage of drug, reasons for not consulting a doctor, duration of self medication, reasons in favour of self medication, reasons against self medication, drug usage pattern and discontinuation of self medication.

The results depicts that significant ' $F$ ' value than the table value for all the self medication practice questions like checking drug before administration $(\mathrm{F}=56.70)$, pattern of medication ( $\mathrm{F}=428.8)$, storage of drug $(\mathrm{F}=103.0)$, reasons for not consulting a doctor $(\mathrm{F}=112.6)$, duration of self medication $(\mathrm{F}=297.4)$, reasons in favour of self medication $(\mathrm{F}=107.4)$, reasons against self medication $(\mathrm{F}=38.4)$, drug usage pattern $(\mathrm{F}=153.8)$ and discontinuation of self medication $(\mathrm{F}=23.7)$. It also depicts that there is significant association existing between self medication practice questions like checking drug before administration, pattern of medication, storage of drug, reasons for not consulting a doctor, duration of self medication, reasons in favour of self medication, reasons against self medication, drug usage pattern and discontinuation of self medication.

Health variables like Occurrence of frequent illness $\left(\chi^{2}=13.0\right)$, type of illness $\left(\chi^{2}=5.7\right)$, self medication type $\left(\chi^{2}=76.9\right)$ and source of knowledge $\left(\chi^{2}=46.2\right)$ have significant association with self medication. Demographic variables like age $\left(\chi^{2}=0.85\right)$, area of residence $\left(\chi^{2}=3.51\right)$, Marital status $\left(\chi^{2}=5.12\right)$, Educational status $\left(\chi^{2}=0.90\right)$ and religion $\left(\chi^{2}=5.2\right)$ and economic variables like Working department $\left(\chi^{2}=5.70\right)$, years of experience $\left(\chi^{2}=1.67\right)$ and family monthly income $\left(\chi^{2}=5.12\right)$ have no significant association with self medication.

ANOVA of women employees based on characteristic health variables reflects that $F$ value is significant for the occurrence of frequent illness $(F=10.23)$ and self medication type $(\mathrm{F}=73.22)$. these values when compared to the table values, are higher therefore researcher rejects null hypothesis (Ho) and it is inferred that there is significant association $n$ between occurrence of frequent illness and self medication type of women employees to their self medication practices.

ANOVA of women employees based on characteristic demographic variables reflects that $\mathrm{F}$ value is not significant for the age $(\mathrm{F}=0.810)$, area of residence ( $F=0.11)$, marital status $(\mathrm{F}=0.018)$, levels of education $(\mathrm{F}=0.454)$ and religion $(\mathrm{F}=0.14)$. As the calculated values are more than the table values, the researcher accepts null hypothesis ( $\mathrm{Ho}$ ) and it is inferred that there is no significant association between age in years, area of residence, marital status, levels of education and religion of women employees to their self medication practices.

ANOVA of women employees based on characteristic economic variables reflects that $\mathrm{F}$ value is not significant for the Working department $(\mathrm{F}=3.55)$, years of work experience $(\mathrm{F}=0.74)$ and family monthly income $(\mathrm{F}=3.63)$ therefore researcher accepts null hypothesis (Ho) and it is inferred that there is no significant association between economic variables like working department, years of work experience and family monthly income of women employees to their self medication practices.

\section{Discussion}

Self medication is widely practiced among women employeesinhealthcareservices duetotheknowledge and hand to hand availability of drugs. It is important to note that heavy dependence of self medication was made on analgesics as well as on other over the counter medicines [10]. The prolonged use of these medicines definitely can be associated with chronic renal failure [11]. The participants in the study show good knowledge towards self medication and positive attitude towards favouring it is acceptable and not a wrong activity in maintaining health in day to day life. Cough \& cold medicines [12], analgesic [13] and antipyretics were most commonly used drugs. Headache, fever, sore throat, and cough were the most common indications for self medication as stated by samples under study. Retail Pharmacies are the main source for procuring self medication drugs [14]. Prevalence of self medication was high due to minor illness and prior experience of diseases. The risk of wrong diagnosis, adverse reaction, drug dependence and delay in seeking medical advice, were the most reasons against self medication practice $[15,16]$. Results obtained will be submitted to the Hospital Authorities and management and 
can take necessary actions in reducing the self medication by conducting workshops, continuous education programmes within hospitals [17].

Wide range of awareness programmes can be systematically planned and conducted on self medication and its adverse effects on health [18]. Exclusive community awareness workshops for women can be organized to explain the complications of non prescription drugs. Request and encourage government and pharmacy organizations to formulate strict policies in supplying and issuance of OTC drugs and explain the need for planning, interventions to control self medication through mass Media such as newspaper, magazine and Television [19].

Authorities should only allow qualified \& eligible pharmacists to sale the drugs, so that potential high risk due to drug dose, duration can be controlled to some extent. Therefore it is suggested that the public has to be educated more on the type of illnesses to be self-diagnosed and medicated, diseases requiring registered practitioner to cure, dangers of OTC drugs, their misuse which possibly would lead to delay in detection of more serious underlying ailments and timely treatment under well trained health care personnel [20].

\section{Conclusion}

The practice of self-medication among future generation health care professionals can be a serious issue and a threat to their professionalism and it has potential ability to put this profession at risk in public trust. Self medication is widely practiced among women employees in health care services due to the knowledge and hand to hand availability of drugs. It is important to note that heavy dependence of self medication was made on analgesics as well as on other over the counter medicines. Reasons for self medication should be identified and measures like personal as well as group counselling should be given to the needy to reduced further use of medicines without prescription. Every pharmacy should strictly follow the government acts in accordance to buying and selling medicines with reference to the government guidelines.

\section{Conflicts of interest}

Authors declare no conflicts of interest.

\section{References}

[1] Dilie A, Gualu T, Haile D, Zuleta FA. Knowledge, attitude and practice of self medication among health science students at Debre Markos University, Northwest Ethiopia. J Public Health Epidem. 2017; 9(5):106-113.

[2] Badiger S. Self medication pattern among medical students in south India. Australas Med J. 2012; 5(4):217-220.

[3] Bradley C, Blenkinsopp A. Over the counter drugs. The future for self medication. BMJ. 1996; 312(7034):835-857.

[4] Christian Nordqvist article on health and illness, online article on health. Available on 31 July 2017; 1-7.

[5] Damodar G. Assessment of self medication practices among medical, pharmacy and nursing students at a tertiary care teaching hospital. Indian J Hospit Pharm. 2012; 49:79-82.

[6] Kaur G, Samuel G, Kaur J. An exploratory study to assess the practices of self medication among women in a selected community of Ludhiana, Punjab. NMRJ. 2011; 7(3):122129

[7] Karthik RC, Gopalakrishnan S. Self medication and its challenges: a review. Res J Pharm, Biolog Chem Sci. 2015; 6(6):388-392.

[8] Montgomery AJ, Bradley C, Rochfort A, Panagopoulos E. A review of self medication in physicians and medical students. Occup Med. 2011, 61(7):490-497.

[9] Jabeen N, Ghani A, Magotra R. Self medication pattern, incidence and factors associated with it, among first year MBBS students of medical college Jammu. J Evol Med Dent Sci. 2015; 4(11):1749-1754.

[10] Babatunde OA, Fadare JO. Self-medication among health workers in a tertiary institution in south-west Nigeria. Pan African Med J. 2016; 24(312):312.

[11] Gupta P. Determinants of self medication practices in an urban slum community. Asian J Pharm Clinic Res. 2011; 4(3):1-5.

[12] Pan H, Cui B, Zhang D, Farrar J, Law F, et al. Prior knowledge, older age, and higher allowance are risk factors for self medication with antibiotics among university students in Southern China. PLoS One. 2012; 27:e41314.

[13] Phalke VD, Phalke DB, Durgawale PM. Self medication practices in rural Maharashtra. Indian J Commun Med. 2006; 31(1):345.

[14] Chaves RG, Lamounier JA, César CC. self medication in nursing mothers and its influence on the duration of breastfeeding. J Pediatr. 2009; 85(2):129-135.

[15] Vargeseet SS, Durgawale PM, Mathew P. Prevalence of self medication in an urban slum area in Maharashtra. JKIMSU. 2013; 2(2):108-110.

[16] Osemene KP, Lamikanra A. A study of the prevalence of self medication practice among university students in southwestern Nigeria. Trop J Pharm Res. 2012; 11(4):683-689.

[17] Rai S, Shanbhag TV, Kumari VP, Pai MRSM. Evaluation of practice of self medication among medical students in a teaching hospital. J Sci Innovat Res. 2015; 4(5):197-199.

[18] Sansgiry SS, Bhansali AH, Bapat SS, Xu Q. Abuse of overthe-counter medicines: a pharmacist's perspective. Integr Pharm Res Pract. 2017; 6:1-6.

[19] Assad T, Karim N, Younus I, Feroz Z. Self medication patterns among undergraduate medical students: a cross sectional institution based study reports. PTB Reports. 2017; 3(2):4346.

[20] Phalke VD, Phalke DB, Durgawale PM. Self medication practices in rural Maharashtra. Indian J Commun Med. 2006; 31(1):34-35. 